\title{
LA-UR- 01-2039
}

Approved for public release; distribution is unlimited.

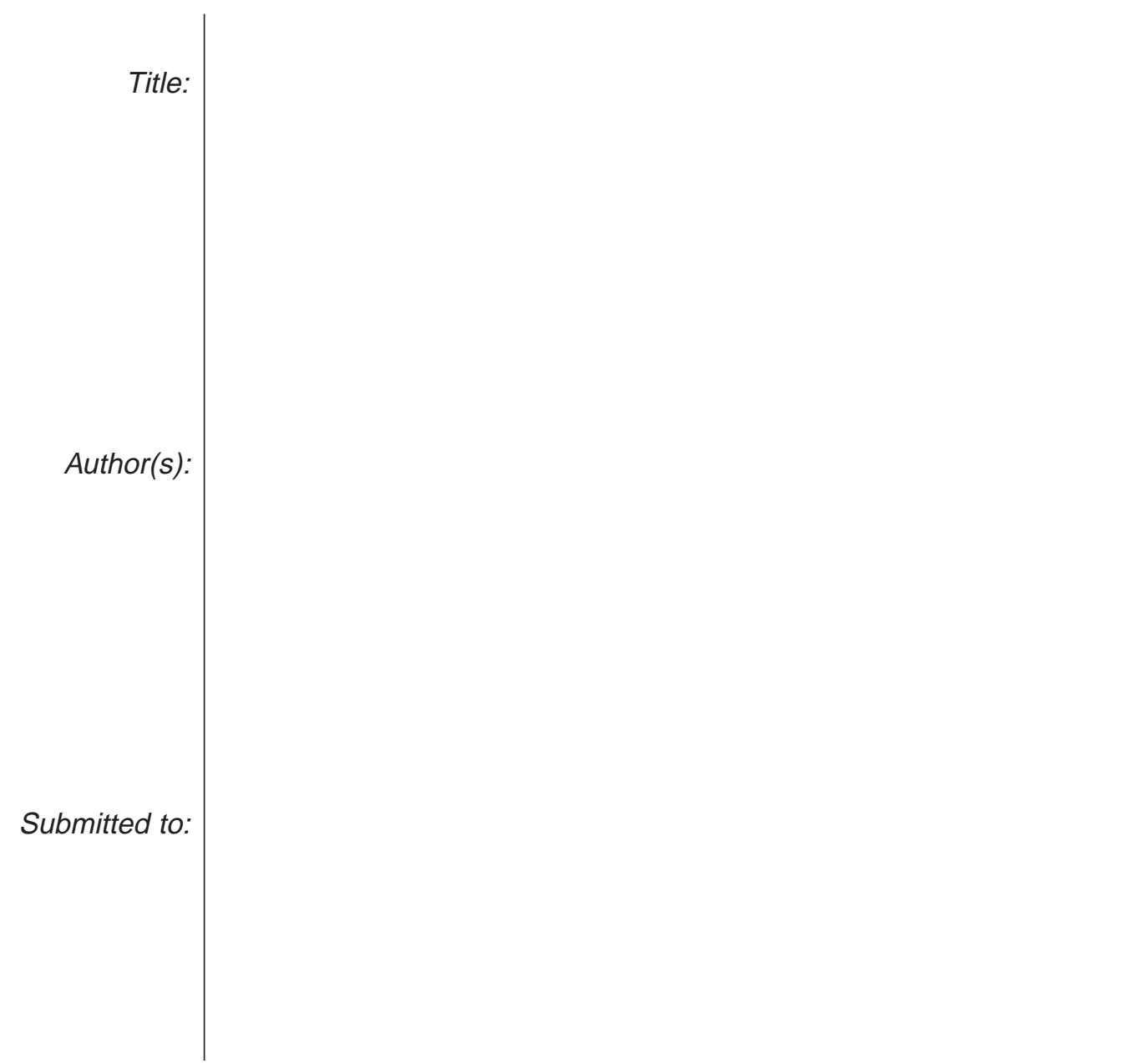

\section{Los Alamos}

NATIONAL LABORATORY

Los Alamos National Laboratory, an affirmative action/equal opportunity employer, is operated by the University of California for the U.S. Department of Energy under contract W-7405-ENG-36. By acceptance of this article, the publisher recognizes that the U.S. Government retains a nonexclusive, royalty-free license to publish or reproduce the published form of this contribution, or to allow others to do so, for U.S. Government purposes. Los Alamos National Laboratory requests that the publisher identify this article as work performed under the auspices of the U.S. Department of Energy. Los Alamos National Laboratory strongly supports academic freedom and a researcher's right to publish; as an institution, however, the Laboratory does not endorse the viewpoint of a publication or guarantee its technical correctness.

Form $836(10 / 96)$ 
IMECE2001-2-20-7-5

\title{
THERMAL ANALYSES AND FREQUENCY SHIFT DESIGN STUDIES FOR THE SPALLATION NEUTRON SOURCE DRIFT TUBE LINAC
}

\author{
Lucie Parietti \\ Engineering Sciences and \\ Applications Division \\ Design Engineering \\ Los Alamos National Laboratory \\ P.O. Box 1663, MS H821 \\ Los Alamos, NM 87545 \\ Email: parietti@lanl.gov
}

\begin{abstract}
Los Alamos National Laboratory is responsible for the design of the room-temperature linac for the Spallation Neutron Source (SNS). This linac consists of a Coupled-Cavity Linac (CCL) and a Drift Tube Linac (DTL). During normal operation, about $80 \%$ of the Radio Frequency (RF) power is dissipated in the DTL cavity walls. This waste heat causes the cavities to expand, causing shifts in their RF resonant frequency. The DTL relies on the water cooling system to compensate for the frequency shift caused by RF heating. To guide the design of the cooling system and the frequency control scheme, thermal expansion and frequency shift studies for several DTL cells are performed via numerical simulations. Temperature distributions and thermal deformations resulting from RF heating are evaluated separately for the tanks and 22 drift tubes using finite element models. The frequency shift of these cells are then computed based on the calculated deformations. Size and locations of the cooling channels are designed accordingly to provide adequate cooling and minimize frequency shift. The tank finite element model used to predict the tank temperature profile is benchmarked against experiment data.
\end{abstract}

\section{INTRODUCTION}

The Spallation Neutron Source (SNS) is an acceleratorbased facility that will be built at Oak Ridge National Laboratory by 2005 . This facility is being designed to meet the needs of the neutron scattering community in the United States. It will produce pulsed beams of neutrons by bombarding a mercury target with intense beams of $1-\mathrm{GeV}$ protons.
A full-energy linac injecting into an accumulator ring has been selected among several technology options for the accelerator system. The beam generated by an ion source is accelerated in the linac, accumulated and bunched in the ring, then extracted and transported to the target.

The SNS project is a collaboration of five national laboratories. Los Alamos National Laboratory is responsible for the room-temperature linac systems. The room-temperature linac takes the beam from the front-end system and accelerates it from $2.5 \mathrm{MeV}$ to $187 \mathrm{MeV}$. It consists of a Drift-Tube Linac (DTL) that accelerates the beam to $86 \mathrm{MeV}$, and a CoupledCavity Linac (CCL) that accelerates the beam to $187 \mathrm{MeV}$.

Under normal operation (beam on), about $80 \%$ of the Radio Frequency (RF) power is dissipated in the cavity walls. The power dissipated causes thermal distortions (i.e., shape change) which result in an RF frequency shift. To zero out the shift caused by RF heating and maintain the desired resonance frequency, each cavity is cooled by forced water circulation. The DTL cooling system is crucial as it provides RF resonance control to the DTL cavities. To guide the design of the cooling system, thermal expansion and frequency shift studies for seven individual DTL cells are performed via numerical simulations.

Finally, the tank finite element model used to predict the tank temperature profile caused by RF heating is validated using experimental data.

\section{NOMENCLATURE \\ E electric field (V) \\ f electromagnetic resonance frequency $(\mathrm{Hz})$ \\ $\mathrm{H}$ magnetic field $(\mathrm{T})$}


$\mathrm{C}_{\mathrm{p}} \quad$ tank section specific heat $(\mathrm{J} \mathrm{kg} / \mathrm{K})$

$\mathrm{R}_{\mathrm{eq}} \quad$ equivalent thermal resistance $(\mathrm{K} / \mathrm{W})$

$\mathrm{T}_{\mathrm{i}} \quad$ temperature of component $\mathrm{i}(\mathrm{K})$

$\mathrm{U} \quad$ cavity stored energy $(\mathrm{J})$

$\mathrm{V}_{\text {steel }}$ volume of tank section $\left(\mathrm{m}^{3}\right)$

$\varepsilon \quad$ permittivity of free space $(\mathrm{T} \mathrm{m} / \mathrm{A})$

$\mu \quad$ permeability of free space $(\mathrm{T} \mathrm{m} / \mathrm{A})$

$\rho \quad$ tank section density $\left(\mathrm{kg} / \mathrm{m}^{3}\right)$

\section{DRIFT TUBE LINAC DESCRIPTION}

The DTL is about $36 \mathrm{~m}$ long and consists of 6 tanks and 210 drift tubes. Each DTL tank combines vacuum envelope and RF structure, and provides mechanical rigidity to the assembly. A tank is made of seamless carbon-steel cylinders with a finished wall thickness of about 2.8 inches $(7.1 \mathrm{~cm})$. The inner diameters are machined and copper-plated to achieve the final dimension and the required surface conductivity. The cylindrical sections are about 2 meters long each and are bolted together to form a tank with RF and vacuum seals at each joint. Tank 1 consists of 2 cylinders, while tanks 3 through 6 consist of 3 sections each. Tank 1 is depicted on Fig. 1.

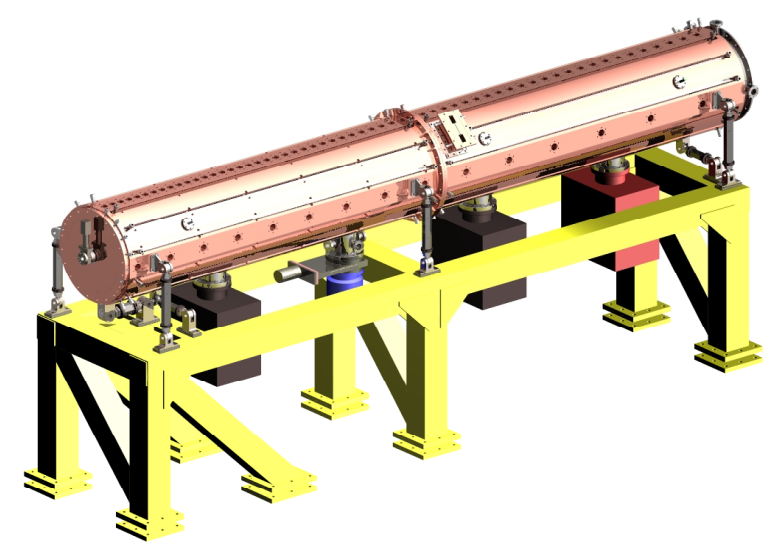

Fig.1 SNS DTL Tank 1.

When the Radio Frequency (RF) is energized, about 206 $\mathrm{kW}$ of RF waste heat are dissipated into the tank walls. To limit the thermal distortions caused by RF heating, the six DTL tanks are cooled by 12 rectangular stainless-steel cooling tubes ( 1 inch wide by 0.5 inches deep) $(2.5$ by $1.3 \mathrm{~cm})$ that are clamped in grooves machined in the tank walls, as shown in Fig. 2. The interstitial gaps between the channels and the tank walls are filled with a non-silicone- thermal grease that improves the heat transfer for heat removal. The thermal grease provides the best design option for the DTL from both installation and thermal performance view points [1].

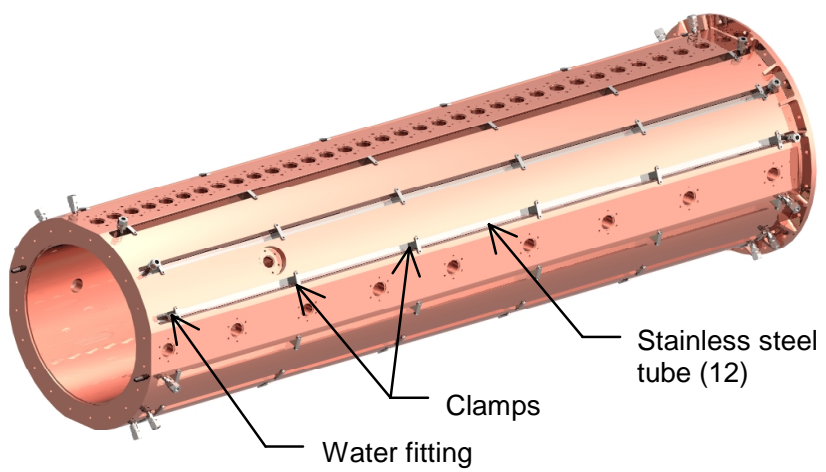

Fig.2 DTL Tank cooling channels.

The geometry of the drift tubes changes with their position along the DTL following the increase in beam energy level. Each drift tube consists of a copper body brazed to a stainless steel stem as shown in Fig. 3. The stem consists of two concentric tubes serving as inlet and outlet ducts for the cooling water. Cooling channels are machined in the drift tube body (see Fig. 3). The cooling water is fed through the outer tube of the stem, splits in half, circulates around the drift tube body in counter direction and exits up the stem inner tube.

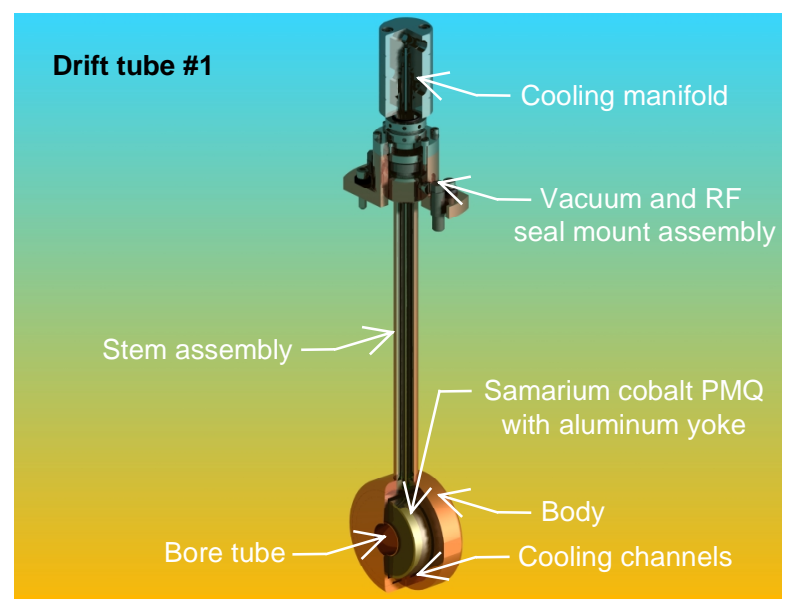

Fig.3 Cut-away view of a typical SNS drift tube.

Figure 4 shows a cross-section of the last drift tube (drift tube \#210). The drift tube body, made of copper, consists of 5 electron-beam (EB) welded parts. The body is brazed to the stainless steel stem before the magnet is inserted. The stem consists of two concentric tubes serving as inlet and outlet ducts for the cooling water. The drift tube body, made of copper, consists of 5 electron-beam (EB) welded parts. The body is brazed to the stainless steel stem before the magnet (Permanent Magnetic Quadrupole, PMQ) is inserted. 

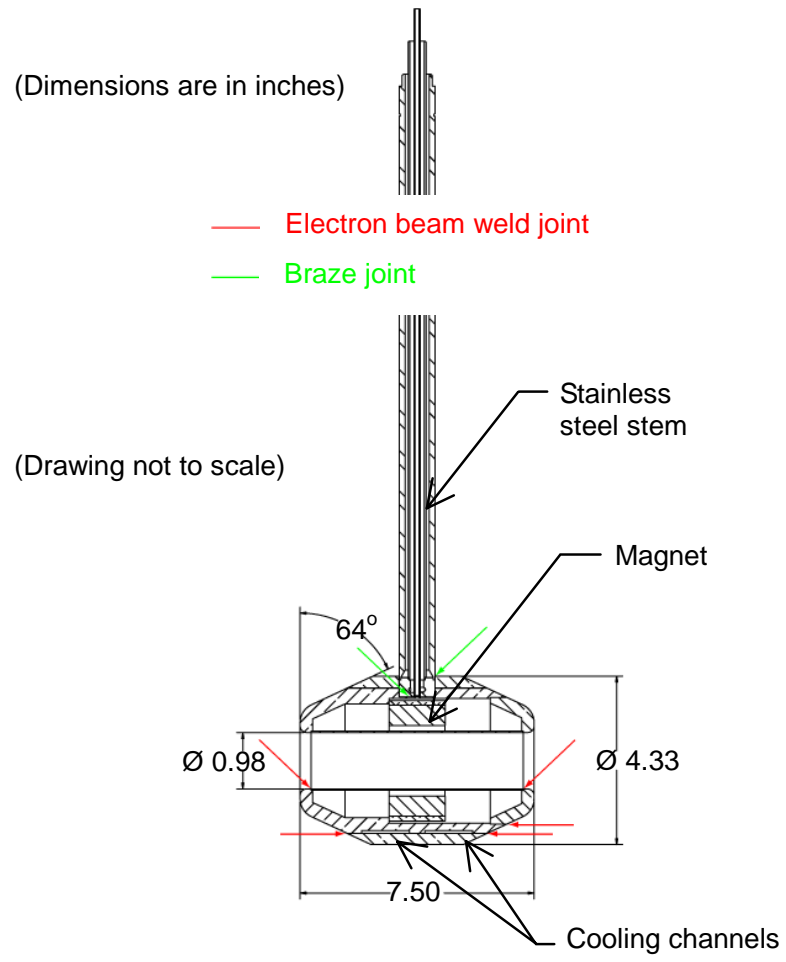

Fig.4 Cross-section of last drift tube of tank 6.

\section{RESONANCE CONTROL PHILOSOPHY}

Under normal operation (beam on), about $80 \%$ of the RF power is dissipated in the cavity walls. This amounts to 370 $\mathrm{kW}$ at a $7.02 \% \mathrm{RF}$ duty factor. The power dissipated causes thermal distortions (i.e., shape change) which result in a resonant frequency shift. To maintain the desired resonance frequency, each cavity is cooled by forced water circulation.

The frequency shifts caused by RF heating can essentially be controlled using three methods. To zero out the frequency shift, one can (1) increase the amount of flow used to cool the cavity, (2) decrease the temperature of the water that is supplied to the cavity, or (3) offset the cavity resonant frequency mechanically by an amount equal to the expected frequency shift. These three methods all have drawbacks. Changing the flow rate in the cavity cooling passages has less impact on the frequency shift than changing the cavity's inlet water temperature. The limiting factor in the flow rate controlled technique is the flow velocity through the cavity cooling passages; excessive velocities can cause large pressure drops and erosion of the soft copper passages. On the other hand, maintaining the resonant frequency by changing the cavity's inlet water temperature is only feasible if the required water temperature is not excessively low. Delivering an inlet temperature close to the chilled water supply temperature from the facility would require excessively high water flow rates through the facility heat exchangers. Finally, controlling the frequency shift by pre-tuning the cavity assumes that the frequency shift caused by RF heating can be predicted accurately. This is why the resonance control scheme should not rely exclusively on this technique. Instead, a combination of (2) and (3) provides the most efficient way of controlling the frequency shift caused by RF heating. Pre-tuning the cavity in addition to controlling the water temperature avoids having to lower the water temperature excessively. It also provides more "tuning" power as the full range of the water adjustment does not have to be used up entirely to compensate for the RF heating induced frequency shift and can be used to correct for additional unforeseen frequency shift anomalies.

\section{FREQUENCY SHIFT DESIGN STUDIES}

Frequency shift studies are performed to guide the design of the cavity cooling passages and the resonance control scheme. To evaluate the frequency shift, temperature distributions and thermal deformations resulting from RF heating are evaluated separately for the tank and several individual drift tubes using finite element models. The frequency shift of these cells are then computed based on the calculated deformations.

Size and location of the cooling channels are designed accordingly to provide adequate cooling and minimize RF heating induced frequency shift. The required offset that will be used as the primary technique to control the resonance control is evaluated based on the cavity frequency shift. The frequency sensitivity of the DTL cavities to variation in water temperature is also evaluated.

\section{Tank Temperature Distribution Caused by RF Heating}

The cooling channels are located radially 1 inch $(2.5 \mathrm{~cm})$ from the inner tank wall and are circumferentially spaced approximately $30^{\circ}$ apart. Taking advantage of the circumferential periodicity of the problem, a two-dimensional finite element model of a $15^{\circ}$ tank section is created using COSMOS/M. The heat fluxes on the inner tank surfaces are calculated with the physics code SUPERFISH (a 10\% safety margin is used). Since the amount of heat deposited on the tank walls increases as the beam energy level increases, the individual channel flow rate is increased from $1.6 \mathrm{gpm}\left(1.0 \times 10^{-}\right.$ $\left.{ }^{4} \mathrm{~m}^{3} / \mathrm{s}\right)$ for tank 1 , to $5 \mathrm{gpm}\left(3.2 \times 10^{-4} \mathrm{~m}^{3} / \mathrm{s}\right)$ for tank 2 and 6.6 gpm $\left(3.8 \times 10^{-4} \mathrm{~m}^{3} / \mathrm{s}\right)$ for tanks 3 through 6 . These flow rates were chosen to induce a temperature rise along the length of a cooling channel of about $2^{\circ} \mathrm{C}$. Heat transfer coefficients corresponding to these flow rates for this channel geometry are applied on the outer edges of the cooling channels to simulate the forced convection boundary condition. All other outer surfaces are assumed adiabatic. To simulate the thermal grease, a layer of elements with a conductivity of $0.7 \mathrm{~W} / \mathrm{mK}$ is added on the bottom groove as well as on the vertical sides (see section Tank Finite Element Model Validation).

The model described above is used to predict the temperature distribution caused by RF heating for all the DTL 
tanks. As an example, Figure 5 shows the temperature distribution for tank 3 when the water running through the cooling channels is at $20^{\circ} \mathrm{C}$. A heat flux of $4862 \mathrm{~W} / \mathrm{m}^{2}$ is applied on the tank inside wall. The resulting average tank temperature is $29.6^{\circ} \mathrm{C}$. This calculated temperature is used later to evaluate the frequency shift of a DTL cell in the drift tube model.

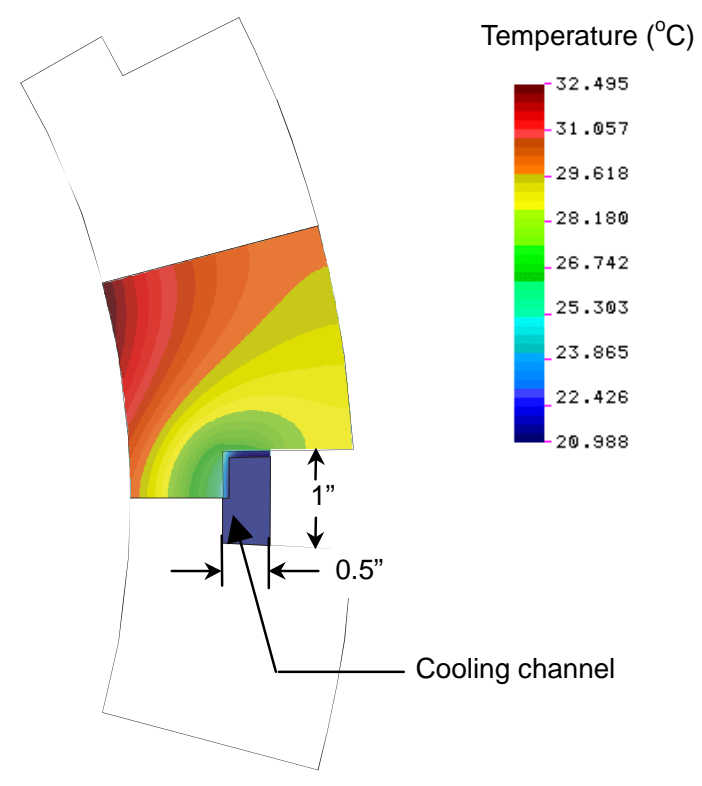

Fig.5 DTL Tank 3 temperature distribution.

\section{Drift Tube Temperature Distribution Caused by RF Heating}

Two-dimensional axisymmetric models for 22 individual drift tubes (the first, the mid and last drift tube of each tank) were built using COSMOS/M. The amount of heat dissipated on the drift tube outside walls is not uniform. The discrete heat flux resulting from RF heating is calculated by SUPERFISH (a $10 \%$ safety margin is used). Note that even though the outside contours of the DTL drift tubes are slightly asymmetric, for simplicity, the set of physical parameters used to build a specific drift tube geometry correspond to the low energy half of the DTL cell where the drift tube is located.

Figure 6 shows the temperature distribution for the last drift tube of tank 3 assuming a water temperature of $20^{\circ} \mathrm{C}$.

The cooling channels are 1.25 inch $(3.18 \mathrm{~cm})$ wide by 0.08 inch $(.20 \mathrm{~cm})$ deep. They are placed as close as possible to the outer surfaces to provide maximum cooling. At the interface between parts, the only efficient heat transfer paths are across the EB welds. Small physical gaps are conservatively included in the model when there is only surface contact between two parts. The flow rate through these cooling channel is limited to $5.1 \mathrm{gpm}\left(3.2 \times 10^{-4} \mathrm{~m}^{3} / \mathrm{s}\right)$ to avoid inducing velocities greater than $2.5 \mathrm{~m} / \mathrm{s}$, which would cause material erosion. This flow rate yields a heat transfer coefficient of $12019 \mathrm{~W} / \mathrm{m}^{2} \mathrm{~K}$ [2].
Note that the drift tube temperature profile is not symmetric, as the EB weld locations are not symmetric. One side of the drift tube is slightly warmer (about $0.8^{\circ} \mathrm{C}$ ) than the other side.

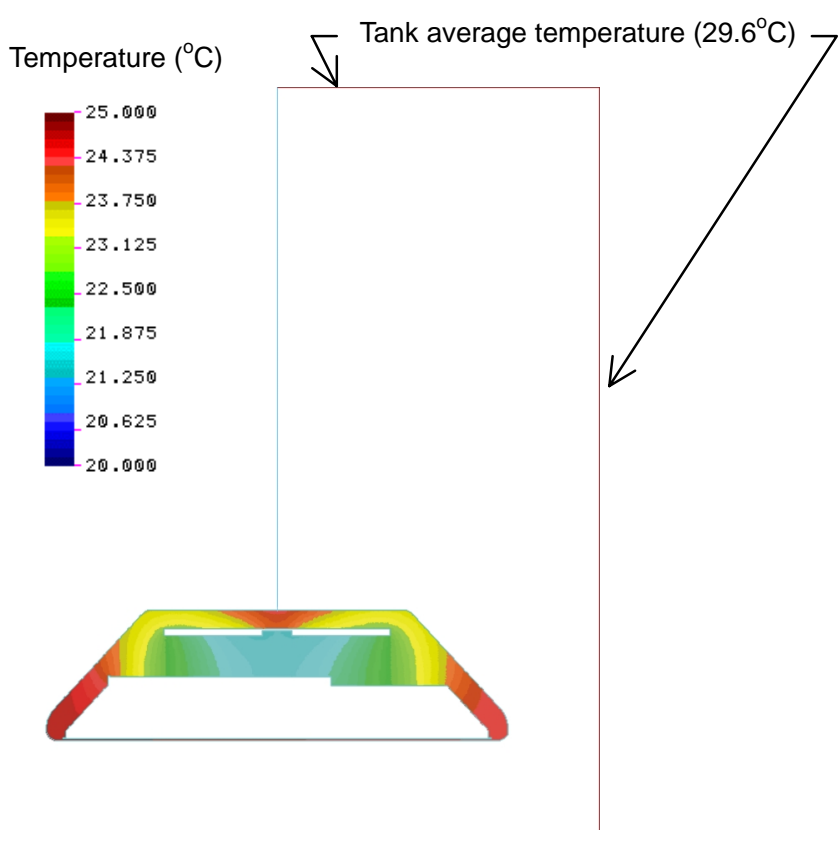

\section{Fig.6 Tank 3 high energy drift tube temperature} distribution.

\section{Frequency Shift}

Thermal distortions caused by RF heating result in a frequency shift as the shape and volume of the cavity changes. For any given cell, the frequency shift can be calculated using the Slater perturbation theory. The change in frequency $d f$ is a function of the volume change of an infinitesimal volume $d V$ at the RF surface, as well as the magnetic and electric fields, $H$ and $E$, on the surface. The frequency shift is given by:

$$
\frac{d f}{f}=\frac{\int\left(\mu H^{2}-\varepsilon E^{2}\right) d V}{4 U},
$$

where $\mu$ and $\varepsilon$ are the free space permeability and permittivity, respectively, $U$ is the stored energy in the cavity and $f$ is the cavity unperturbed electromagnetic resonance frequency.

For a DTL, both the tank deformations (radial and longitudinal) and the drift tube deformations contribute to the total frequency shift. To account for the tank deformation, beam elements are added to the drift tube model previously described. These beam elements, as shown in Fig. 6, are set to a uniform temperature corresponding to the average tank wall temperature to simulate the radial and the longitudinal growth 
of the tank. The thermal deformations corresponding to the drift tube and the tank temperature profile are then solved using the COSMOS/M finite element package. A separate Fortran code reads the displacements output by the finite element package and computes the frequency shift of the cell. Note that because the drift tube temperature profile is not symmetric, the deformation is not the same on either side of the drift tube. All the frequency shift values reported here are an average frequency shift corresponding to deformations on both sides of the drift tube.

\section{Cavity Cooling Channel Design Studies}

To avoid field errors, all the DTL cells should resonate at the same frequency. If the scheme described above is used to control resonance, then the frequency shift caused by RF heating should be the same for all the DTL cells. However, the heat dissipated on the cavity inner surfaces increases as the beam energy level increases. Because of drastic differences in heat load from one tank to another, frequency shift studies have shown that the cooling system can not be designed such that the six DTL tanks have the same frequency shift as a result of RF heating. Instead, each tank will be individually pre-tuned mechanically to a given frequency; the resonance frequency of each tank (with no power) will be offset of an amount equal to its frequency shift. This offset will allow all six tanks to operate as the same desired resonant frequency during power operation and will place the $402.5 \mathrm{MHz}$ operating point within range of the RF control system.

Within each tank, each cell should have the same frequency shift. Because the heat dissipated on the drift tube outside walls increases as the cell length increases, the simplest way to induce the same frequency shift for all the cells within the same tank is to increase the flow rate delivered to each drift tube. However, for tanks 1 and 2, the amount of heat dissipated on the drift tube outside walls between the low-energy and the high-energy end differs by a factor of 9 and 2, respectively. Therefore, keeping the same cooling channel design for these drift tubes is not practical. In addition to changing the flow, the width of the cooling channels is tailored to keep the flow turbulent. The height of the cooling channel $(0.08 \mathrm{in}, .20 \mathrm{~cm})$ is kept constant for all drift tubes. The width of the cooling channel increases as the energy level increases. For tanks 3 through 6 , the amount of RF heating does not increase as much between the low-energy end and the high-energy end within each tank. Therefore, only changing the flow rate is adequate to compensate for the increase in RF heating and reach the same frequency shift.

The frequency shift caused by RF heating for the six DTL tanks varies between $-14 \mathrm{kHz}$ for tank 1 to $-61 \mathrm{kHz}$ for tank 6 and is shown in Table 1.

Since both the tank deformations (radial and longitudinal) and the drift tube deformations contribute to the frequency shift, the cooling system can be used in several ways to zero out the frequency shift caused by RF heating. Proper resonant frequency can be achieved by either changing the temperature of the water in the drift tubes and/or changing the temperature of the water in the tank walls. If one wants to control the resonant frequency by changing the water temperature in the DTL cavities, the frequency sensitivity to water temperature changes should be the same for all six tanks. Studies have shown that this can be achieved by changing the temperature of the water delivered to the cavity in both the tank and the drift tubes. The average sensitivity of the DTL system is about 6 to $7 \mathrm{kHz} /{ }^{\circ} \mathrm{C}$.

\begin{tabular}{|l|c|c|c|c|c|c|}
\hline Tank & 1 & 2 & 3 & 4 & 5 & 6 \\
\hline Frequency shift $(\mathrm{kHz})$ & -14 & -49 & -31 & -39 & -46 & -61 \\
\hline
\end{tabular}

\section{Table 1: DTL tank frequency shift caused by RF heating.}

Since both the tank deformations (radial and longitudinal) and the drift tube deformations contribute to the frequency shift, the cooling system can be used in several ways to zero out the frequency shift caused by RF heating. Proper resonant frequency can be achieved by either changing the temperature of the water in the drift tubes and/or changing the temperature of the water in the tank walls. If one wants to control the resonant frequency by changing the water temperature in the DTL cavities, the frequency sensitivity to water temperature changes should be the same for all six tanks. Studies have shown that this can be achieved by changing the temperature of the water delivered to the cavity in both the tank and the drift tubes. The average sensitivity of the DTL system is about 6 to $7 \mathrm{kHz} /{ }^{\circ} \mathrm{C}$.

\section{TANK FINITE ELEMENT MODEL VALIDATION}

A test assembly representing a single cooling channel was built and tested. This prototype was used in several ways. It was used to test the procedure required to assemble the cooling channels, verify experimentally the effectiveness of the thermal grease as a heat transfer path, and benchmark the tank finite element model used to predict the tank temperature profile.

\section{Experimental Approach}

The tank test rig (see Fig. 7) consists of a 4.5 inches (11.4 $\mathrm{cm}$ ) wide by 2.8 inches $(17.1 \mathrm{~cm})$ high carbon steel rectangular section. The section width is typical of the spacing between two successive cooling channels. The height corresponds to the actual tank thickness. The rectangular cooling channel is made of a 1 inch $(2.5 \mathrm{~cm})$ wide by 0.5 inches $(1.3 \mathrm{~cm})$ high stainless steel tubing and sits in a groove that is manufactured with the same tolerances as the actual grooves to be machined in the tank walls. The distance between the cover plates that hold the channel in place corresponds to the typical distance between two cover plates. The interstitial gaps between the channels and the tank walls are filled with a thermal grease that provides the heat transfer path for heat removal. 


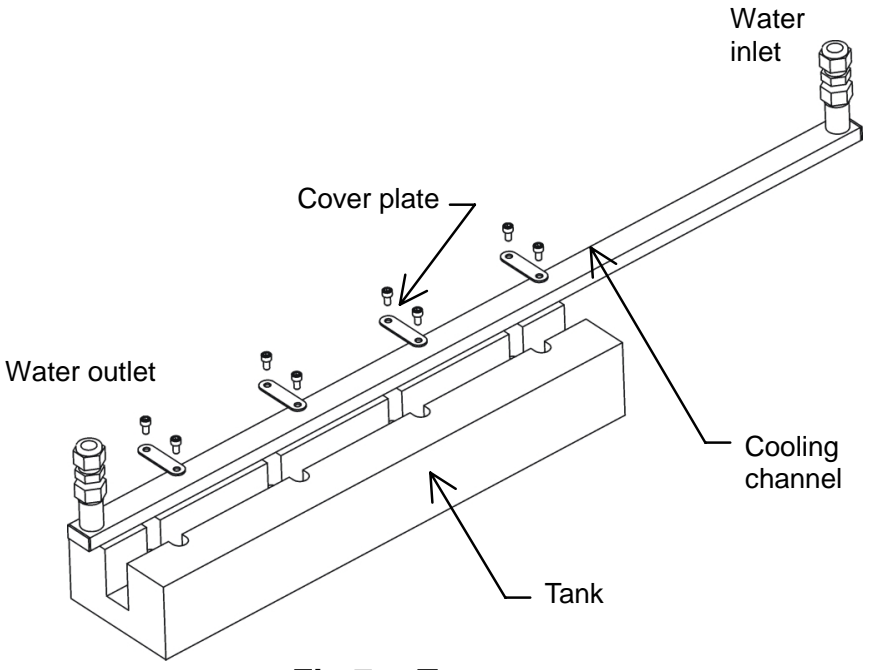

Fig.7 Test set-up.

A simple transient test was conceived to assess the effectiveness of the thermal grease and validate the finite element model of the tank. By starting at room temperature equilibrium and suddenly circulating cold water in the cooling channel, one can estimate the effective thermal resistance of the system by measuring the temperature of the steel section representing the tank as a function of time. Initially, both the cooling channel and the carbon-steel section are at a uniform initial temperature $T_{\text {init }}$. At time $\mathrm{t} \geq 0$, water at a temperature $T_{\text {water }}$ is circulated through the cooling channel. Assuming the thermal mass of the grease and the channel are negligible compared to the thermal mass of the carbon-steel section, the temperature of the steel tank $T_{\text {steel }}$ is given by:

$$
\frac{T_{\text {steel }}-T_{\text {water }}}{T_{\text {init }}-T_{\text {water }}}=e^{\frac{-1}{R_{\text {eq }}} \cdot \frac{1}{\rho \cdot C_{p} \cdot V_{\text {steel }}} \cdot t},
$$

where $V_{\text {steel }}$ is the volume of the tank section, $\rho$ its density and $C_{p}$ its specific heat. $R_{e q}$ designates the equivalent thermal resistance of the system, and accounts for the heat transfer from the water to the inside wall of the cooling channel, across the wall of the cooling channel, across the thermal grease layer and into the carbon-steel section.

The initial slope of the normalized tank temperature given by Eq. (2) provides a direct measure of the overall thermal resistance of the system, $R_{e q}$ and is equal to:

$$
\frac{d}{d t}\left[\frac{T_{\text {steel }}-T_{\text {water }}}{T_{\text {init }}-T_{\text {water }}}\right]_{t \approx 0}=-\frac{1}{R_{e q}} \cdot \frac{1}{\rho \cdot C_{p} \cdot V_{\text {steel }}} .
$$

This simple transient test presents several advantages over a steady state test. The instrumentation required is simpler as the thermocouples only need to be mounted on the outside walls of the tank, rather than at each material interface. The thermocouples calibration is much less critical since the transient test provides a direct measure of the overall thermal resistance by measuring the cool-down slope and therefore eliminates the need to measure accurately very small temperature differences across the different material interfaces. Only a cold source is needed as opposed to both hot and cold sources for a steady state test. Finally, the temperature stability of the cold source is not critical.

\section{Experimental Apparatus}

The experimental set-up to conduct this simple transient test described is shown in Fig. 8. The tank cooling channel prototype is covered with a 2 inch $(5.1 \mathrm{~cm})$ thick foam box to thermally insulate it from the ambient air and connected to a chiller (Neslab HX-75) that has its own circulation pump.

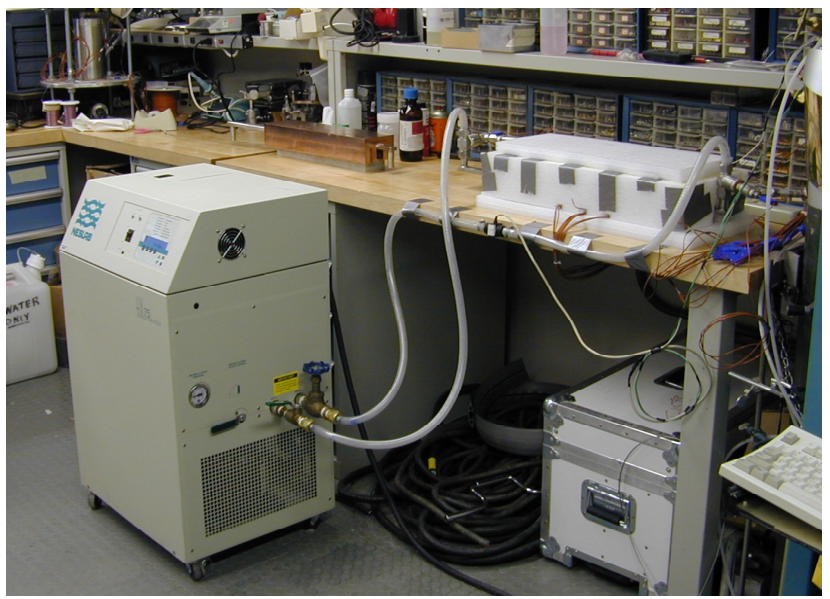

Fig.8 Test set-up.

A globe valve is mounted on the return side of the chiller to adjust the amount of flow delivered to the test section. A ball valve, mounted on the supply side of the chiller, allows the test section to be isolated from the chiller. When this valve is closed, the water bypasses the test section and recirculates continuously inside the chiller (the chiller recirculating valve has to be closed as well). The chiller can deliver a maximum of $4 \mathrm{gpm}\left(2.5 \times 10^{-5} \mathrm{~m}^{3} / \mathrm{s}\right)$. A flow meter (Omega FTB-603) is mounted in the line connecting the test section to the chiller return side. The flow meter is fastened to the bench in order to provide the adequate lead length upstream and downstream. Two thermocouples measure the temperature of the water entering and exiting the test section. Fifteen thermocouples are mounted on the prototype outside walls to record the temperature during the transient test. The temperature data are collected with a Hewlett Packard 34970A data acquisition system controlled with a custom Labview 5.0 application running on an IBM PC. 


\section{Model Validation}

The temperature distribution on the tank walls due to $\mathrm{RF}$ heating was calculated using a finite element model. In this model, several assumptions were made. The thermal resistance of the thin thermal grease layer was estimated based on the thermal conductivity given by the manufacturer. The heat transfer coefficient of the water running through the cooling channels was estimated using a correlation for smooth pipes [2]. This model must be validated experimentally if one wants to rely on its predictions.

The temperatures recorded experimentally are compared against temperatures predicted by a finite element model. A 2D model of the mock-up section is created using COSMOS/M. Taking advantage of the symmetry of the problem, only half of the prototype is modeled. A schematic of the model is shown on Fig. 9.

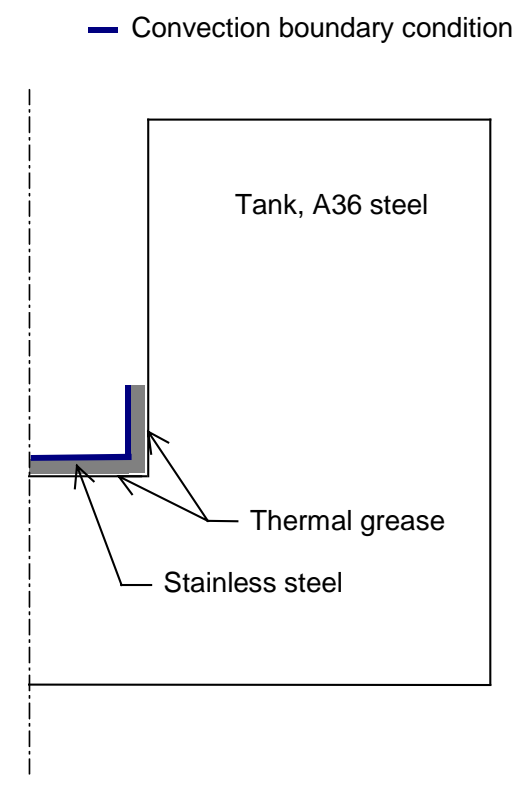

Fig.9 Tank FE model schematic.

Initially, the temperature is set to $20^{\circ} \mathrm{C}$. Starting at time $\mathrm{t}=0$, a $1.5 \mathrm{gpm}\left(9.5 \times 10^{-5} \mathrm{~m}^{3} / \mathrm{s}\right)\left(4 \mathrm{gpm}, 2.5 \times 10^{-5} \mathrm{~m}^{3} / \mathrm{s}\right)$ flow rate through the cooling channel is assumed. This flow rate corresponds to a water velocity of $0.5 \mathrm{~m} / \mathrm{s}(1.2 \mathrm{~m} / \mathrm{s})$ and gives an expected heat transfer coefficient of $2118 \mathrm{~W} / \mathrm{m}^{2} \mathrm{~K}(4641$ $\left.\mathrm{W} / \mathrm{m}^{2} \mathrm{~K}\right)$. This heat transfer coefficient is applied on the outer edges of the cooling channel to simulate a forced convection boundary condition. All other surfaces are assumed to be adiabatic. The thickness of the thermal grease layer on the bottom groove was measured on the prototype. The layer was about .002-in. $(.005-\mathrm{cm})$ thick. In the model, a .002-in. (.005 $\mathrm{cm})$ thermal grease layer is therefore assumed on the tank bottom groove. The vertical gaps are assumed .02-in. $(.05-\mathrm{cm})$ wide based on fabrication drawings and filled with thermal grease. The material properties for the thermal grease used in the model are based on data given by the manufacturer.

Temperatures predicted by the model at a location corresponding are compared with experimental data in Fig. 10 for two different flow rates, 1.5 and $4 \mathrm{gpm}\left(9.5 \times 10^{-5} \mathrm{~m}^{3} / \mathrm{s}\right.$ and $2.5 \times 10^{-5} \mathrm{~m}^{3} / \mathrm{s}$ ). Very good agreement exists between data predicted by the finite element model and experimental data.

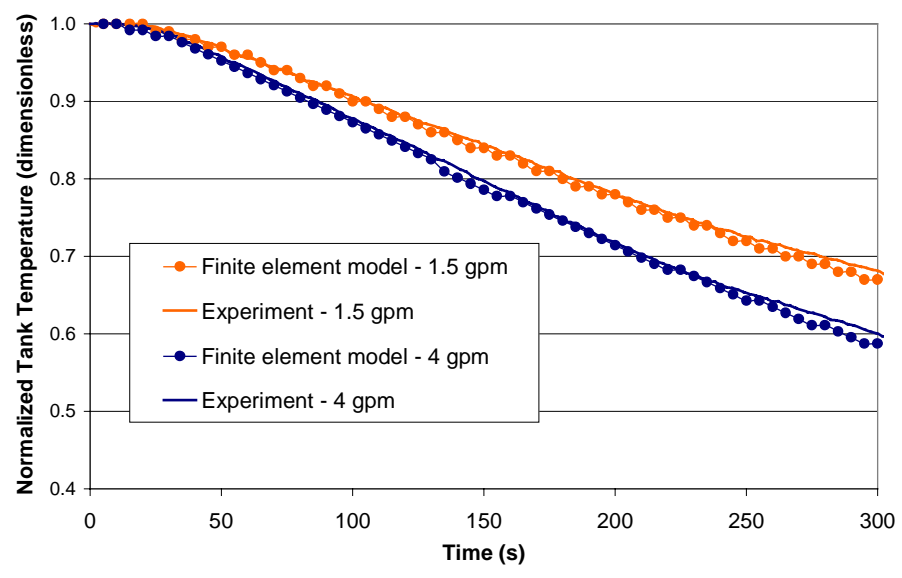

Fig.10 Tank FE model benchmark.

\section{CONCLUDING REMARKS}

The cooling system of the DTL is crucial since it provides resonant frequency control for the DTL cavities. To support the design of this cooling system, frequency shift studies for 22 DTL cells were performed using numerical simulations. The tank and the drift tubes will be cooled on the same circuit; the DTL resonant frequency will be maintained by adjusting dynamically the water temperature in both the drift tubes and the tank walls. To avoid fields errors and frequency mismatch within a single tank, a uniform frequency shift for all the DTL cells contained in this tank is obtained by balancing the flow rate and tailoring the cooling channels for each individual drift tube. The frequency shift caused by RF heating varies from one tank to the next. It varies from $-14 \mathrm{kHz}$ for tank 1 to $-61 \mathrm{kHz}$ for tank 6 at a $7.0 \%$ duty factor. From a practical standpoint, each tank will be tuned during final assembly to a predetermined frequency to give a nominal $402.5 \mathrm{MHz}$ resonance during powered operation. The temperature of the flowbalanced system can also be adjusted during operation to correct for additional frequency shift. Lowering (increasing) the inlet temperature by $1.0^{\circ} \mathrm{C}$, produces a negative (positive) frequency shift of about 6 to $7 \mathrm{kHz}$.

The finite element model used to simulate the experiment predicts the heat transfer performance extremely well. Therefore, a finite element model of the DTL tank using the same assumptions should simulate accurately the temperature distribution caused by RF heating. 


\section{REFERENCES}

1. Parietti L., 2000, "Testing of the Tank Cooling Scheme for the Spallation Neutron Source (SNS) Drift Tube Linac," Technical report LA-UR-00-3623, Los Alamos National Laboratory.

2. Incropera, F. P. and DeWitt, D. P., 1990, Fundamentals of Heat Transfer, 3rd ed., John Wiley \& Sons, Inc., New York, NY. 